\title{
Partial Purification and Characterization of Smooth Muscle Relaxant Extracted from the Slime Mold Physarum Polycephalum
}

\begin{abstract}
Shinji Yoshiyama
Background and Aims: Vasculature of plasmodia of Physarum polycephalum exhibits the repeated cycles of contraction and relaxation. By the analogy of smooth muscle which shows the cycles, I speculated the presence of vasodilator (s), and/or vasoconstrictor (s) in the plasmodia and tried to extract active principle (s).

Materials and Methods: The extract partially purified from the plasmodia was applied to rabbit femoral artery and guinea pig ileum. The mode of effect was analyzed by measuring tension of intact and demembranated smooth muscle cells and by measuring phosphorylation of $20-\mathrm{kDa}$ myosin light chain (MLCK20).

Results : The extract relaxed the smooth muscles in a dose-dependant manner. The active principle is shown to be resistant to hydrolysis by acid and alkaline and to have a low molecular weight. The relaxation effect on the intact cells was absent with the demembranated cells. The relaxing was not associated with the change in MLC20 phosphorylation.

Conclusion: I obtained a crude extract from plasmodia which relaxes smooth muscle. The mode of relaxing is discussed with special reference to the development a vasodilatory drug with a new mode of action. (Kitakanto Med J 2004; $54: 189 \sim 196)$
\end{abstract}

Key words : Smooth muscle, Physarum polycephalum, Vasodilator, Natural product, Myosin phosphorylation

\section{Introduction}

The contractile force of smooth muscle derives from the interaction between actin and myosin. The activation of the interaction by phosphorylatiry $20-\mathrm{kDa}$ myosin light chain (MLC20) has been established for many years. ${ }^{1}$ Upon stimulation by vasoconstrictor, the intracellular concentration of $\mathrm{Ca}^{2+}$ of vascular smooth muscle is elevated, causing $\mathrm{Ca}^{2+}$ to bind to calmodulin $(\mathrm{CaM})$. CaM complexed with $\mathrm{Ca}^{2+}(\mathrm{Ca} /$ $\mathrm{CaM}$ ) activates myosin light chain kinase (MLCK). Myosin phosphorylated at MLC20 by MLCK is in active form and interacts with actin to induce contraction. ${ }^{2}$ However, there are many examples of discrepancy between the MLC20 phosphorylation and contraction of smooth muscle. For example, uterine smooth muscle can contract in $\mathrm{Ca}^{2+}$-free medium by using oxytocin as an agonist. In this case, $\mathrm{Ca}^{2+}$ was not elevated, and MLC20 was not phosphorylated. ${ }^{3}$
Recently, Kohama and his colleagues have shown that MLC20 phosphorylation is not obligatory for smooth muscle myosin to be activated (Ye et al 1999 PNAS) ${ }^{4}$ and that non-kinase activity of MLCK is responsible for the activation (Gao et al for review 2001). ${ }^{5}$

The regulators that exert their role extracellularly are widely known as vasodilators and vasoconstrictors. In many cases, they are derived from natural resource. I interested in plasmodia of Physarum polycephalum, lower eukaryotes that live on moist areas such as found in forests, as the resouce. The plasmodia are full of vascularity to exhibit rapid cytoplasmic streaming, which is caused by the repeats of contraction and relaxation due to interaction between actin and myosin. ${ }^{6} \quad$ By the analogy of smooth muscle that shows the repeat, I speculate that vasodilator(s) and/or vasoconstrictor (s) might be present in plasmodia.

In this study, I obtained a crude extract from plasmodia and examined its effect with a rabbit femor-

1 Department of Molecular and Cellular Pharmacology, Faculty of Medicine, Gunma University Graduate School of Medicine 3-39-22 showa-Machi, Maebashi, Gunma 371-8511 Japan

Received: January 20, 2004 Accepted : July 2, 2004

Address: SHINJI YOSHIYAMA Department of Pharmacology, Faculty of Medicine, Gunma University, 3-39-22, Showa-Machi, Maebashi, Gunma 371-8511 Japan. 
al artery and guinea pig ileum by measuring an isometric contraction, and found that vasodilatory action in a fraction of the extract. When the effect was related with the phosphorylation of MLC20, the artery relaxed without changing the extent of the phosphorylation of MLC20.

\section{Materials and Method}

\section{Materials}

Plasmodia of Physarum polycephalum (strain $\mathrm{Ng}$ -1) were grown on rolled oats (Quaker Oats Company, Chicago, IL, USA) in the dark by the method of Camp with some modifications. ${ }^{7,8}$ Migrating sheets of plasmodia were collected and used for the experiments.

\section{Chemicals}

All chemicals were commercial products of reagent grade. Solutions were made in Milli Q water (Milli Q Plus, Millipore, Bedford, MA, USA). Acetylcholine chloride was purchased from Daiichi Pharmaceutical Co., Ltd., Tokyo, Japan. Alpha-toxin was purchased from Sigma, St. Louis, MO, USA. 1-phenylephrine hydrochloride, and $1 \mathrm{H}-[1,2,4]$ oxadiazolo $[4,3,-\mathrm{a}]$ quinoxalin-1-one (ODQ) were purchased from Wako Pure Chemical Industries Co., Ltd., Osaka, Japan. Sodium nitroprusside dihydrate (SNP) was purchased from Alexis Biochemicals, San Diego, CA, USA.

\section{Extraction of smooth muscle relaxant}

Plasmodia were frozen and stored at $-80^{\circ} \mathrm{C}$ after washing with water purified by reverse osmosis membrane (Elix-UV, Millipore). The frozen plasmodia were homogenized on ice in same volume of extraction solution that consisted of $1 \mathrm{M} \mathrm{CH}_{3} \mathrm{COOH}$ and $20 \mathrm{mM}$ $\mathrm{HCl}$. The homogenate was centrifuged at $250,000 \times \mathrm{g}$ for $1 \mathrm{~h}$ to obtain a yellow supernatant, which was then passed through a $0.45 \mu \mathrm{m}$ membrane filter (Millex ${ }^{\circledR}$ -LH, Millipore) followed by lyophilization by centrifugal concentrator CC-100 (Tomy, Tokyo). The material was suspended in ethanol and allowed to stand for 1 hour at $-80^{\circ} \mathrm{C}$. This suspension was then centrifuged at $15,000 \times \mathrm{g}$ for $2 \mathrm{~h}$ and the supernatant was lyophilized. The lyophilized sample was dissolved in $0.1 \%(\mathrm{v} / \mathrm{v})$ trifluoroacetic acid (TFA), and then applied to a reversed phase column of Sephasil Protein C4 $12 \mu$ ST $(4.6 \times 250 \mathrm{~mm}$, Amersham Pharmacia Biotech, Buckingham, UK) that was connected to a high-performance liquid chromatography (HPLC) system (L-6200, L-4000, D-6000, Hitachi, Tokyo). The column was washed with solution A of $0.1 \%(\mathrm{v} /$ v) TFA, and the bound materials were then eluted by solution B of $90 \%(\mathrm{v} / \mathrm{v})$ acetonitrile in $0.1 \%(\mathrm{v} / \mathrm{v})$ TFA with a linear gradient from solution A to solution $\mathrm{B}$ at a flow rate $1 \mathrm{ml} / \mathrm{min}$. The yellow fractions

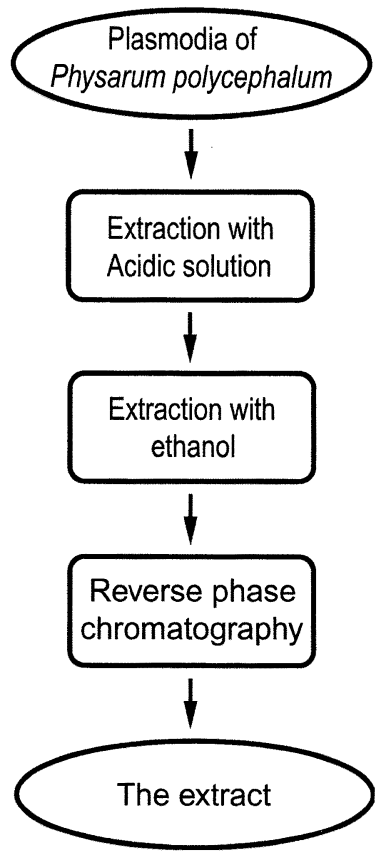

Fig.1. Preparation of the extract from plasmodia of Physarum polycephalum. The procedures described in Materials and Methods were summarized. The extract was then used for the experiments in Fig.2. Fig.7.

that were eluted from $5 \%$ to $25 \%$ of solvent B were collected. The eluted fractions were lyophilized as described above and stored at $-30^{\circ} \mathrm{C}$. The above steps were summarized in Fig.1. This frozen stock was used as "the extract" in isometric contraction studies of Fig. $3 \sim 7$ and a MLC20 phosphorylation assay. Approximately $0.14 \mathrm{mg} / \mathrm{ml}$ of the extract was defined expediently as the extract $(\times 1)$. The number in parentheses of $(\times 1)$ indicated a relative concentration of the extract.

A part of the extract was hydrolyzed with a small volume of $6 \mathrm{~N} \mathrm{HCl}$ at $110^{\circ} \mathrm{C}$ for $24 \mathrm{~h}$ or $5 \mathrm{~N} \mathrm{NaOH}$ at $70^{\circ} \mathrm{C}$ for $5 \mathrm{~h}$ and lyophilized as described above. This hydrolysate was partitioned into water-soluble and lipid-soluble portions by the method of Bligh \& Dyer. ${ }^{9}$ The upper water phase after partitioning was subjected to an HPLC system with a column of SP -TOYOPEARL $650 \mathrm{~S}(0.6 \times 10 \mathrm{~cm}$, TOSOH, Tokyo), which was equilibrated with $75 \%$ (v/v) methanol. The flow-through of resin was then dried. The dried material was dissolved in $75 \%(\mathrm{v} / \mathrm{v})$ methanol and was subjected to an HPLC system using a Sephadex LLH-20 $(1.0 \times 30 \mathrm{~cm}$, Amersham Pharmacia Biotech) after equilibration by $75 \%(\mathrm{v} / \mathrm{v})$ methanol. The fractions containing activity of relaxing smooth muscle were detected by an isometric tension measurement of Fig. 2 (see following sections). 


\section{Smooth muscle preparation and tension measure- ments}

I prepared the following solutions. The smooth muscle organ stock solution consisted of $137.4 \mathrm{mM}$ $\mathrm{NaCl}, 5.9 \mathrm{mM} \mathrm{KCl}, 1.2 \mathrm{mM} \mathrm{CaCl}_{2}, 1.2 \mathrm{mM} \mathrm{MgCl}_{2}, 0.2 \%$ $(\mathrm{w} / \mathrm{v})$ glucose, and $11.6 \mathrm{mM}$ 4-(2-hydroxyethyl)-1 - piperazineethanesulfonic acid (HEPES) at $\mathrm{pH} 7.3$ adjusted with $\mathrm{NaOH}$. The normal extracellular solution (NES) consisted of $150 \mathrm{mM} \mathrm{NaCl}, 4 \mathrm{mM} \mathrm{KCl}, 2$ $\mathrm{mM}$ calcium methanesulfonate, $1 \mathrm{mM}$ magnesium methanesulfonate, and $5 \mathrm{mM}$ HEPES at $\mathrm{pH} 7.4$ adjusted with Tris (hydroxymethyl) aminomethane (Tris). The $\mathrm{Ca}^{2+}$-free normal extracellular solution $\left(\mathrm{Ca}^{2+}\right.$-free NES) was NES which consisted of $1 \mathrm{mM}$ ethyleneglycol bis (2-aminoethylether) tetraacetic acid (EGTA) instead of $2 \mathrm{mM}$ calcium methanesulfonate. The high potassium extracellular solution (KES) consisted of $150 \mathrm{mM}$ potassium methanesulfonate, $4 \mathrm{mM} \mathrm{KCl}, 2$ $\mathrm{mM}$ calcium methanesulfonate, $1 \mathrm{mM}$ magnesium methanesulfonate, and $5 \mathrm{mM}$ HEPES at $\mathrm{pH} 7.4$ adjusted with Tris. The normal intracellular solution (G1) consisted of $74.1 \mathrm{mM}$ potassium methanesulfonate, 2 $\mathrm{mM} \mathrm{Mg}^{2+}, 4.5 \mathrm{mM}$ adenosine triphosphate $\left(\mathrm{Mg}^{2+}\right.$ -ATP), $1 \mathrm{mM}$ EGTA, 10mM creatine phosphate, and 30mM 1,4-piperazinebis (ethane sulfonic acid) (PIPES) at $\mathrm{pH} 7.1$ adjusted with $\mathrm{KOH}$. The desired concentration of free $\mathrm{Ca}^{2+}$ was obtained by $\mathrm{Ca}^{2+}$ -EGTA buffer.

All experiment procedures were approved by the Animal Care and Experimentation Committee of Gunma University. Rabbits (Japanese white) weighing 2.5 to $3.0 \mathrm{~kg}$ and guinea pigs weighing $200 \mathrm{~g}$ were purchased from Imai jikkendoubutu shiikujo (Saitama, Japan). Rabbits were anesthetized with pentobarbital sodium intravenously. The femoral artery was removed quickly and immersed in ice-cold smooth muscle organ stock solution and then stored at $4^{\circ} \mathrm{C}$. I used the femoral arteries of the rabbits within one week. The guinea pigs were anesthetized with diethyl ether and sacrificed. The ileum was removed and immersed in the same stock solution. I used the ileum on the same day. I dissected the rabbit femoral artery into small strips, 200 to $300 \mu \mathrm{m}$ wide and $5 \mathrm{~mm}$ long for the tension measurement and into a small sheet ( $2 \mathrm{~mm}$ wide $\times 5 \mathrm{~mm}$ long) for measuring MLC20 phosphorylation simultaneously with the tension measurement. I removed the basal membranes, including endothelial cells, from the strips and sheets of rabbit femoral artery.

The strips and sheets of rabbit femoral artery were set between a hook and an isometric force transducer (AE801; AME, Horten, Norway) connected to an amplifier (Union, Gunma, Japan) and a pen recorder (SS-100F, SEKONIC, Tokyo, Japan) on a $400 \mu 1$ bubble plate ${ }^{10}$ at $24 \pm 0.5^{\circ} \mathrm{C}$. I loaded the strips and sheets with approximately $100 \mu \mathrm{N}$ as the resting tension in NES. The guinea pig ileum, $1.5 \mathrm{~cm}$ long, was set vertically between a hook and an isometric force transducer (Nihon Kohden Ltd., Tokyo, Japan) connected to an amplifier (Nihon Kohden) and a polygraph (Nihon Kohden) in a $10 \mathrm{ml}$ magnus tube at room temperature.

\section{Permeabilization with a-toxin}

The strip of rabbit femoral artery was connected to an isometric force transducer as described above. The bubble plate was chilled to less than $10^{\circ} \mathrm{C}$, after which I changed from NES to $\mathrm{G} 1$, including $30 \mu \mathrm{g} / \mathrm{ml}$ of alpha-toxin. ${ }^{11,12}$ The strips were then incubated for $30 \mathrm{~min}$ at $38^{\circ} \mathrm{C}$ and washed twice in $\mathrm{Gl}$ at $24^{\circ} \mathrm{C}$ for $10 \mathrm{~min}$.

\section{Measurement of MLC20 phosphorylation in smooth muscle}

The phosphorylated MLC20, separated from unphosphorylated MLC20 by glycerol-PAGE, ${ }^{13,14}$ was detected by western blotting with the monoclonal antibody against MLC20 (Clone MY-21, Sigma). Femoral artery sheets prepared were connected to the force transducer as described above and then preincubated in NES that included various amounts of the extract. The NES contained in the organ bath was then replaced by KES containing $50 \mu \mathrm{M}$ phenylephrine, which allowed the sheet to contract. The sheet was flash-frozen in the medial of contraction with a reaction stop solution containing $10 \%$ trichloroacetic acid (TCA) in acetone with $10 \mathrm{mM}$ DTT that had been chilled by dry ice. The femoral artery sheets were air dried after a wash in acetone with $10 \mathrm{mM}$ DTT to remove TCA. The dried femoral artery sheets were mixed with a urea sample buffer consisting of $20 \mathrm{mM}$ Tris, $22 \mathrm{mM}$ Glycine, 10mM DTT, $8.3 \mathrm{M}$ urea, and $0.1 \%$ bromphenol blue for $1 \mathrm{~h}$ at room temperature. The samples were filtered through a $0.45-\mathrm{mm}$ membrane filter (UltrafreeR-MC, Millipore) and subjected to glycerol-PAGE, followed by transfer to a polyvinylidene difluoride (PVDF) membrane (Immobilion $^{\mathrm{TM}}$ PVDF Transfer Membrane, Millipore) in transfer buffer consisting of $25.0 \mathrm{mM}$ Tris, $38.4 \mathrm{mM}$ glycine, and $20 \%$ methanol. The membrane was blocked with $5 \%$ skim milk in PBS-T consisting of $0.1 \%$ Tween 20 in phosphate-buffered saline. The membrane was reacted with anti-MLC20 antibody for $1 \mathrm{~h}$ at room temperature. ${ }^{15}$ The membrane was then reacted with sheep anti-rabbit IgG secondary antibodies conjugated by horseradish peroxidase (Amersham Pharmacia Biotech). I detected MLC20 phosphorylation by a shift of the MLC20 band with an 
enhanced chemiluminescent detection system (ECL Plus Western Blotting Detection System, Amersham Pharmacia Biotech). Western blots were quantified by densitometry using the NIH IMAGE program, Version 1.63 .

\section{Results}

Extraction of a crude fraction with activity to relax smooth muscle from plasmodia of Physarum polycephalum

I obtained an extract of $13.6 \mathrm{mg}$ dry weight from 100 $\mathrm{g}$ (wet weight) of plasmodia of Physarum polycephalum by the method described in the Materials and Methods section. The aqueous fraction, partitioned from the hydrolysate after the acid treatment by the Biligh \& Dyer method, was applied to the femoral artery, which was contracted by KES. I found that the fraction effectively relaxed the artery (data not shown). The effect was not lost by hydrolysis of alkaline and acid substances, and thus the active principle was stable against hydrolysis. The aqueous fraction was passed through a cation exchange column. I detected the relaxation effect in the flow-through, indicating that the active principle bound to the cation exchange resin (data not shown). Figure 2 depicts a typical record of gel permeation chromatography. There were several evident absorbance peaks, among which relaxing activity was detected in the fractions with retention times of 34 to $42 \mathrm{~min}$ (Fig.2)

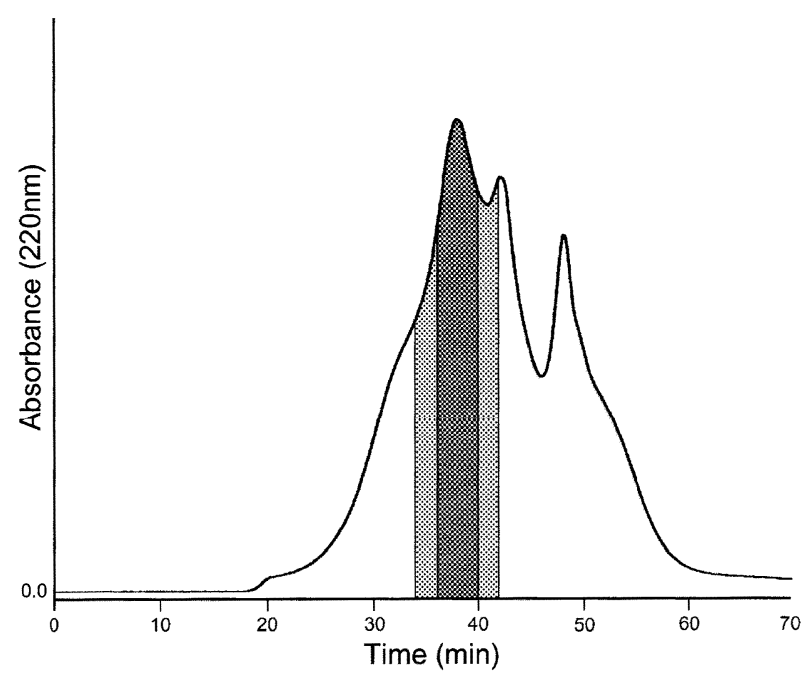

Fig.2. Gel permeation chromatography with the Sephadex LH -20 column of the extract, which was partially purified from Physarum polycephalum. The effluents, including the active principle, are indicated in light gray, or in dark gray when the relaxing activity was maximum. The elution solution was $75 \%(\mathrm{v} / \mathrm{v})$ methanol, and the flow rate of the elution solution was $0.4 \mathrm{ml} / \mathrm{min}$.

\section{Effect of the extract on rabbit femoral artery}

I next quantitatively examined the relaxing activity of the extract by adding various amounts of the extract to NES in an organ bath containing the femoral artery. I also added a vehicle for the control. The pretreated artery was then contracted by changing the media to KES containing the same amounts of extract. KES induced a phasic contraction of the rabbit femoral artery followed by a tonic contraction of the control artery. The phasic contraction of this control was 1 . $14 \mathrm{mN}$. The tension at the peak of the phasic contraction with pre-treatment in NES by the extract $(X 1, \times$ 2) was $91.4 \%$ and $52.7 \%$ of the control. The increase of the extract $(\times 3, \times 4$ and $\times 5)$ appeared to obscure the phasic contraction, leaving only a tonic contraction. For $15 \mathrm{~min}$ after allowing the artery to were 94 . $3 \%(\times 1), 86.7 \%(\times 2), 83.9 \%(\times 3), 74.3 \%(\times 4)$, and $3.9 \%(\times 5)$ of the control (Fig. $3 \mathrm{~A})$.

The effect of post-treatment with the extract was also observed during tonic contractions in KES (Fig. 2B). KES-induced tension of the tonic contraction of the control was $0.94 \mathrm{mN}$. The tension was decreased by cumulative addition of the extract to $86.9 \%(\times 2)$, $56.1 \%(\times 4), 14.7 \%(\times 6)$, and $13.1 \%(\times 8)$ of the control (Fig. 3B). The extract then effectively relaxed the tonic contraction post-treatment.
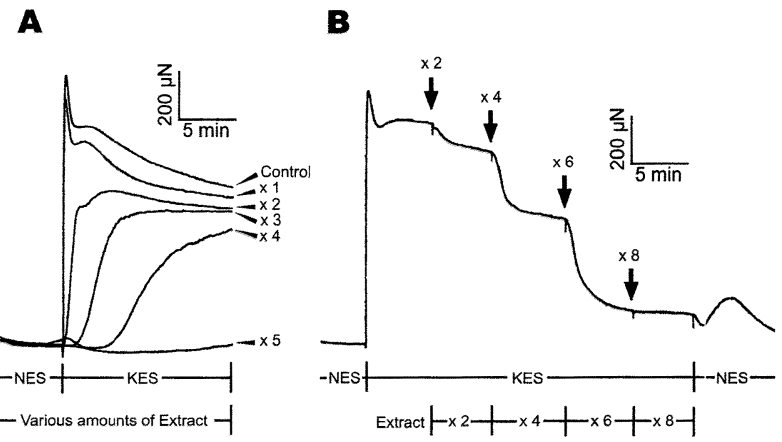

Fig.3. Relaxing effect of the extract on the contraction of rabbit femoral artery induced by KES. A small strip of rabbit femoral artery was stabilized in NES. Changing the medium in the organ bath to KES resulted in KES-induced strong phasic contraction and subsequent weak tonic contraction.

A. Effect of pre-treatment. The strip was preincubated in NES at $24^{\circ} \mathrm{C}$ for $5 \mathrm{~min}$ in various amounts of the extract before stimulation with KES. The strip was preincubated in the vehicle as a control, and was contracted by KES in the absence of the extract. The strip was then contracted by KES containing various amounts of the extract. B. Effect of after-treatment. The femoral artery was contracted by KES. The extract was added cumulatively to KES during the tonic phase, as indicated by the arrows.

\section{Effect of ODQ on relaxation induced by the extract}

The strip was contracted with KES for $10 \mathrm{~min}$ as a control, and then incubated with NES until the tension returned to the base tone. ODQ $(5 \mu \mathrm{M})$, an inhibitor of soluble guanylate cyclase, ${ }^{16,17}$ was applied to the strip during the contraction induced by KES. ODQ inhibition was confirmed with inhibition of the relaxa- 
tion by sodium nitroprusside $(100 \mu \mathrm{M})$. A four-fold increase in the dosage of the extract was applied to the strip in the presence of ODQ. However, I failed to detect any significant difference in the relaxation effect (data not shown).

\section{Effect of the extract on guinea pig ileum}

I observed results similar to those for rabbit femoral artery (Fig.3B) in acetylcholine (ACh) -induced contractions of the guinea pig ileum (Fig.4). The tension of the contraction induced with ACh $(0.5 \mu \mathrm{M})$ of the control was $12.70 \mathrm{mN}$. The contraction was maintained constant for up to $30 \mathrm{~min}$. The tension was decreased in every application of the extract to $92.6 \%(\times 1), 35.0 \%(\times 2), 14.8 \%(\times 3)$, and $2.7 \%(\times$ 4) of the control (Fig.4). I concluded that the contraction induced with $\mathrm{ACh}$ in guinea pig ileum was dose-dependently suppressed by application of the extract.

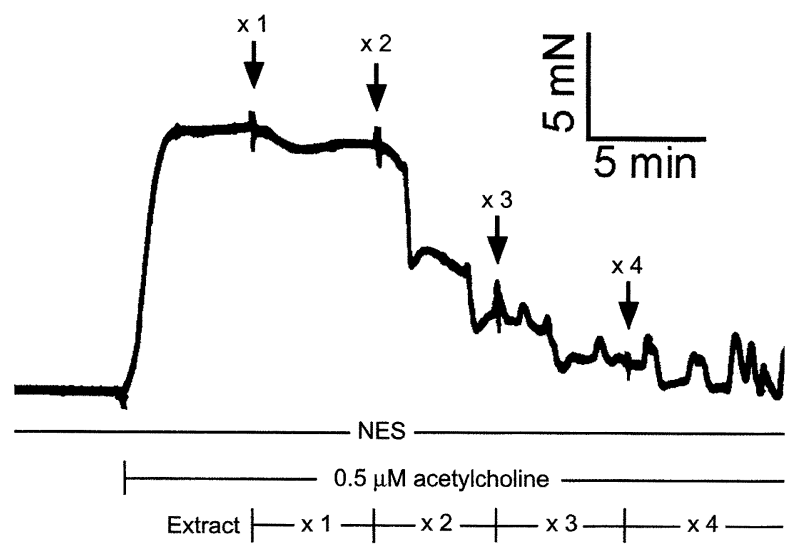

Fig.4. Relaxation effect of the extract on ACh-induced contraction of guinea pig ileum. Dissected guinea pig ileum was stabilized in NES, in the same way as was the femoral artery. ACh $(0.5 \mu \mathrm{M})$ was added to the ileum. The extract was applied to the organ bath cumulatively after the contraction reached a stable plateau.

\section{Inhibitory effect of the extract on the femoral artery contraction under $\mathrm{Ca}^{2+}-$ free conditions}

Phenylephrine can induce transient contractions in the rabbit femoral artery in the absence of $\mathrm{Ca}^{2+} \cdot{ }^{18,19}$ The tension of the contraction induced with phenylephrine $(50 \mu \mathrm{M})$ in $\mathrm{Ca}^{2+}-$ free NES as a control was 0.54 $\mathrm{mN}$. The tension at the peak of the contraction was 93.1\% (×1), 79.3\% (×2), 62.0\% (×3), 51.7\% (×4), $31.0 \%(\times 5)$, and $2.0 \%(\times 6)$ of the control (Fig.5). I observed a delay of the contraction tension prior to the peak. The peak time of the control contraction induced with phenylephrine in $\mathrm{Ca}^{2+}$-free NES was 1.56 min. The peak time of the contraction treated with the extract was $1.77 \mathrm{~min}(\mathrm{x} 1), 2.71 \mathrm{~min}(\times 2), 4.69$ in $(\times$ $3), 6.88 \mathrm{~min}(\times 4)$, and $9.48 \mathrm{~min}(\times 5)$. The contraction due to phenylephrine was undetectable from the basal
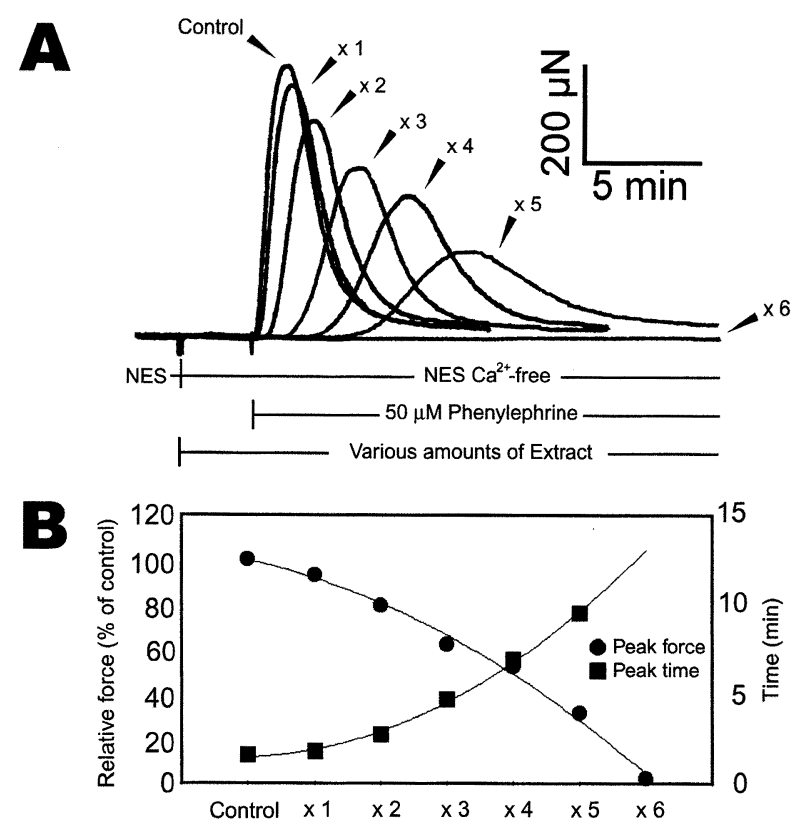

Fig.5. Relaxing effect of the extract on contraction of rabbit femoral artery induced by phenylephrine stimulation in $\mathrm{Ca}^{2+}-$ free NES.

A. The strip of femoral artery was stabilized in NES. The phenylephrine $(50 \mu \mathrm{M})$ stimulation caused a phasic contraction in the strip under $\mathrm{Ca}^{2+}$-free NES. The strip was preincubated at $24^{\circ} \mathrm{C}$ for $3 \mathrm{~min}$ with various concentrations of the extract in $\mathrm{Ca}^{2+}$-free NES after resting in NES for over $20 \mathrm{~min}$. The control strip was preincubated and stimulated by phenylephrine without the extract at the same time.

B. The relative force (O) and time of the force development peak (ם).

tone when $I$ increased the extract to $\times 6$. The dose -response relationship of the peak tension and delay is presented in Fig.5B.

Effect of the extract on rabbit femoral artery permeabilized with alpha-toxin

I prepared a membrane permeabilized artery by treatment with alpha-toxin. The contraction of this prepared artery induced by pCa 5.0 was $1.75 \mathrm{mN}$. I did not observe significant suppression of the force development induced by the extract. The force development was decreased to $100.0 \%(\times 2), 99.0 \%(\times 4)$, and $96.5 \%(\times 6)$ of the control every two times I applied various dosages of the extract to the artery (Fig. 6). This indicates that the extract exerted little effect on the membrane permeabilized artery.

\section{Effect of the extract on MLC20 phosphorylation in smooth muscle}

The femoral artery was contracted by phenylephrine under depolarized conditions, i.e., in KES. The extract relaxed the tension. The concentration -dependent relaxation is indicated by dark bars in Fig. 7. The phosphorylation of MLC20 was examined by 


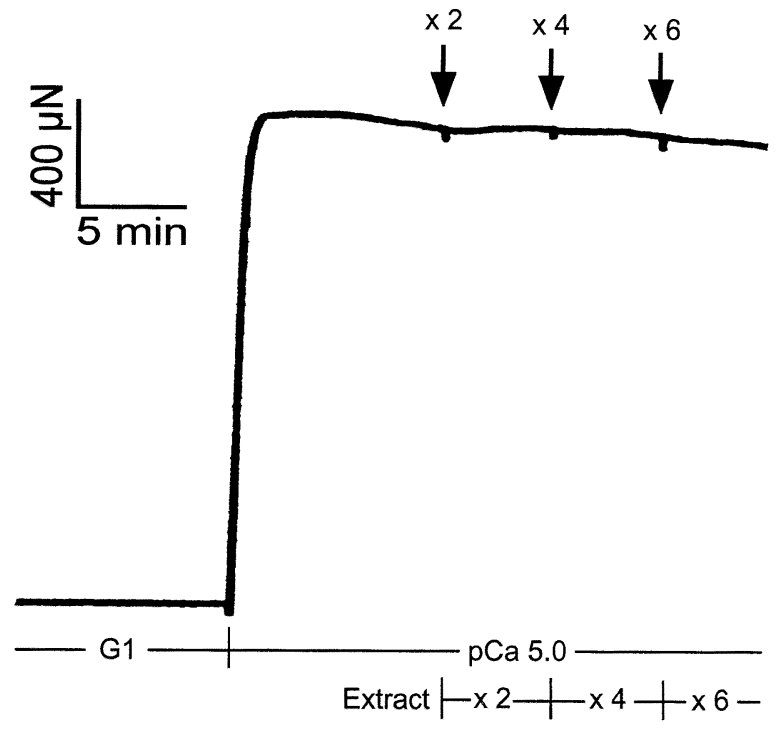

Fig.6. Effect of the extract on rabbit femoral artery permeabilized with alpha-toxin. The strip was stabilized in G1 after permeabilization with alpha-toxin and washing with G1. The extract was cumulatively applied to the strip when the intracellular solution, including $10 \mu \mathrm{M}$ free $\mathrm{Ca}^{2+}$ (pCa 5.0), stably induced contraction.

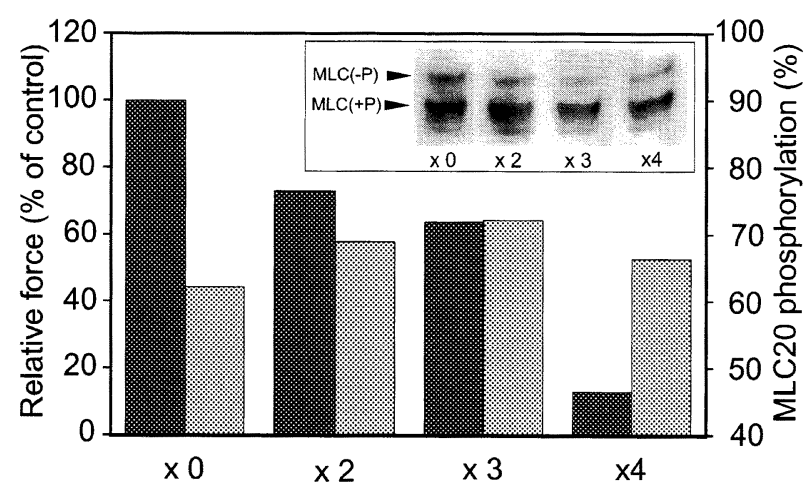

Fig.7. MLC20 phosphorylation in rabbit femoral artery. The femoral artery was excised to form a sheet to measure MLC20 phosphorylation and tension at the same time. The sheet was connected to the transducer as depicted in Fig.2, and the sheet was then contracted by phenylephrine $(50 \mu \mathrm{M})$ in KES. The contraction was stopped by rapid freeze and was subjected to analysis of MLC20 phosphorylation, as described in Materials and Methods. The inset shows the Western blot. MLC $(-\mathrm{P})$ and MLC (+ P) denote the MLC20 bands of the unphosphorylated form and the phosphorylated form. The dark gray bar represents the contraction tension and the light gray bars represent MLC20 phosphorylation. Each tension was normalized by the control tension, and the degree of phosphorylation is expressed as $\operatorname{MLC}(+\mathrm{P}) / \mathrm{MLC}(+\mathrm{P})$ plus MLC (-P).

freezing the artery quickly, as described in Materials and Methods, followed by a combination of urea glycerol PAGE and Western blot. The level of MLC20 phosphorylation was not altered by the extract, as indicated by the bright bars in Fig. 7.

\section{Discussion}

The active principle of the present study bound strongly to the reverse phase resin, indicating that it is not an inorganic salt. The extract is very stable, having retained activity through hydrolysis in $6 \mathrm{~N} \mathrm{HCl}$ or $5 \mathrm{~N}$ NaOH. Physarum lysophosphatidic acid (PHYLPA) was previously isolated from plasmodia as an inhibitor of DNA polymerase alpha. ${ }^{20}$ Cyclic lysophosphatidic acid, an analogue of PHYLPA, increases intracellular cAMP concentration. ${ }^{21}$ This suggests that the extract contains PHYLPA. However, the active principle in the extract differs from PHYLPA in regard to its resistance against alkaline hydrolysis. The essential structure of active principle to exert an activity doesn't include peptide bonds, ether linkage and esteratic site. The active principle of the present study was not dissolved in organic solvents such as chloroform (data not shown), leading me to predict that it is not lipophilic but amphiphilic or hydrophilic material. The gel-permeation experiment indicated that the relaxing factor might be a small molecule less than $4 \mathrm{kDa}$.

The extract inhibited both the phasic contraction and tonic contraction induced by depolarization with potassium stimulation in a dose-dependent manner, as illustrated in Fig. 3. This effect was independent of endothelial cells, since the endothelial cells were removed from all strips for the tension measurement. The rabbit femoral artery and guinea pig ileum could be readily relaxed by the extract (Figs. 3 and 4), suggesting that this effect is similar to a calcium antagonist or an inactivator of calcium channel. Phenylephrine induces calcium release from endoplasmic reticulum and calcium influx via a receptor-operated calcium channel. ${ }^{22}$ I contracted the samples in a $\mathrm{Ca}^{2+}$-free solution in the present study. Therefore, the extract relaxed the femoral artery just by calcium release from the endoplasmic reticulum (Fig.5). The degree of relaxation was extended by adding the extract, and the period of tension was extended by adding the opposite extract (Fig.5). Therefore, it is possible that the degree of calcium efflux from the endoplasmic reticulum decreases or calcium reuptake into the endoplasmic reticulum increases. These data indicate that the active principle in extract from plasmodia may not exhibit this property with calcium antagonists.

The question arises whether this relaxing effect is brought about indirectly by some mediators or directly by interacting with contractile proteins, such as the actomyosin system. I examined the direct relaxant action on contractile proteins using a permeabilization model of rabbit femoral artery. The permeabilized model allows membrane-impermeable substances to enter the cells and can constantly maintain the intracel- 
lular fluid condition. The femoral artery permeabilized with alpha-toxin was not affected by the extract (Fig.6), suggesting that the relaxant affected the contractile proteins indirectly through a membrane, such as a receptor.

NO donors, typified by nitroglycerin, are well known as smooth muscle relaxation factors. ${ }^{23}$ Cyclic guanosine monophosphate (cGMP) is produced by NO-activated soluble guanylate cyclase. I attempted to block this signaling pathway with ODQ. The effect of this relaxant was not changed by the inhibitor. thus, the vasodilator of the present study may not be related to the soluble guanylate cyclase pathway.

It is an accepted hypothesis that myosin phosphorylation in MLC20 is an active form in the development of smooth muscle cells., ${ }^{1,2}$ However, the phosphorylation of MLC20 in this study was not altered when contraction was decreased by the extract (Fig.7). This is not unexpected, since my laboratory ${ }^{3,5}$ and others ${ }^{4,24}$ have reported that MLC20 is not the sole pathway to developing tension in smooth muscle.

\section{Acknowledgement}

I am deeply indebted to Professor K. Kohama for guidance as this study was carried out. His advice during this study and the completion of this thesis is greatly appreciated. Thanks are also due to Dr.A. Nakamura for supervising the purification and the planning of the experiments, and to Dr.K. Iizuka for instruction for the isometric study.

Last but not least, I would like to thank all of my colleagues at the Department of Molecular and Cellular Pharmacology for their encouragement.

\section{References}

1. Kamm K. E, Stull J. T. The function of myosin and myosin light chain kinase phosphorylation in smooth muscle. Annu. Rev. Pharmacol. Toxicol $1985 ; 25: 593-620$.

2. James T, Joanna K, Krueger KE, et al. Myosin Light Chain Kinase. In : Barany M (eds). Biochemistry of smooth muscle contraction. San Diego : Academic Press, 1996: 119-130.

3. Ye LH, Kishi H, Nakamura A, et al. Myosin light-chain kinase of smooth muscle stimulates myosin ATPase activity without phosphorylating myosin light chain. Proc. Natl. Acad. Sci. USA $1999 ; 96: 6666-6671$.

4. Oishi K, Takano-Ohmuro H, Minakawa-Matsuo $\mathrm{N}$, et al. Oxytocin contracts rat uterine smooth muscle in $\mathrm{Ca} 2(+)$-free medium without any phosphorylation of myosin light chain. Biochem Biophys Res Commun 1991; 176: 122-128.

5. Gao Y, Ye LH, Kishi H, et al. Myosin light chain kinase as a multifunctional regulatory protein of smooth muscle contraction. IUBMB Life $2001 ; 51: 337-344$.

6. Nakamura A, Kohama K. Calcium Regulation of the Actin-Myosin Interaction of Physarum polycephalum. Int Rev Cytol 1999; 191: 53-98.

7. Kohama K, Ishikawa $\mathrm{R}$, Ishigami $\mathrm{M}$. Large -Scale Culture of Physarum: A Simple Way of Growing Plasmodia to Purify Actomysin and Myosin. In: JULIO EC (eds). Cell Biology: A Laboratory Handbook, Second Edition. Vol. 1. Sun Diego: Academic Press, 1998: 466-471.

8. Hohenester E, Maurer $\mathrm{P}$, Hohenadl $\mathrm{C}$, et al. Structure of a novel extracellular $\mathrm{Ca}(2+)$-binding module in BM-40. Nat Struct Biol 1996; 3 : 67-73.

9. Bligh EG, Dyer WJ. A rapid method of total lipid extraction and purification. Can J Med Sci 1959; 37 : 911-917.

10. Horiuti K. Mechanism of contracture on cooling of caffeine-treated frog skeletal muscle fibres. J Physiol 1988; 398: 131-148.

11. Nishimura J, Kolber M, van Breemen C. Norepinephrine and GTP-gamma-S increase myofilament $\mathrm{Ca}^{2+}$ sensitivity in alpha-toxin permeabilized arterial smooth muscle. Biochem Biophys Res Commun 1988; 157: 677-683.

12. Kitazawa $\mathrm{T}$, Kobayashi S, Horiuti $\mathrm{K}$, et al. Receptor-coupled, permeabilized smooth muscle. Role of the phosphatidylinositol cascade, G-proteins, and modulation of the contractile response to $\mathrm{Ca}^{2+}$. J Biol Chem 1989; $264: 5339-5342$.

13. Sakurada K, Seto M, Sasaki Y. Dynamics of myosin light chain phosphorylation at Ser 19 and Thr18/Ser19 in smooth muscle cells in culture. Am J Physiol 1998; 274 : 1563-1572.

14. Kishi H, Mikawa T, Seto M, et al. Stable transfectants of smooth muscle cell line lacking the expression of myosin light chain kinase and their characterization with respect to the actomyosin system. J Biol Chem 2000; 275: 1414-1420.

15. Sasaki Y, Uchida T, Sasaki Y. A variant derived from rabbit aortic smooth muscle: phenotype modulation and restoration of smooth muscle characteristics in cells in culture. J Biochem (Tokyo) 1989; 106: 1009-1018.

16. Moro MA, Russel RJ, Cellek S, et al. cGMP mediates the vascular and platelet actions of nitric oxide: confirmation using an inhibitor of the soluble guanylyl cyclase. Proc Natl Acad Sci USA 1996; 93 : 1480-1485.

17. Olson LJ, Knych ET Jr, Herzig TC, et al. Selective guanylyl cyclase inhibitor reverses nitric oxide -induced vasorelaxation. Hypertension 1997; 
$29: 254-261$.

18. Heaslip RJ, Rahwan RG. Norepinephrine-induced contractions of the rat aorta in the absence of extracellular calcium-II. Effects of calcium antagonists. Gen Pharmacol 1983; 14 : 505-512.

19. Nishimura K, Ota M, Ito K. Existence of two components in the tonic contraction of rat aorta mediated by alpha 1 -adrenoceptor activation. $\mathrm{Br}$ J Pharmacol 1991; 102: 215-221.

20. Murakami-Murofushi K, Shioda M, Kaji K, et al. Inhibition of eukaryotic DNA polymerase alpha with a novel lysophosphatidic acid (PHYLPA) isolated from myxoamoebae of Physarum polycephalum. J Biol Chem 1992; 267 : 21512-21517.

21. Mukai M, Imamura F, Ayaki M, et al. Inhibi- tion of tumor invasion and metastasis by a novel lysophosphatidic acid (cyclic LPA). Int J Cancer 1999; 81: 918-922.

22. Guimaraes S, Moura D. Vascular adrenoceptors: an update. Pharmacol Rev 2001; 53: 319-356.

23. Hennan JK, Diamond J. Effect of NO donors on protein phosphorylation in intact vascular and nonvascular smooth muscles. Am J Physiol Heart Circ Physiol 2001 ; 280 : 1565-1580.

24. Bao J, Oishi K, Yamada T, Liu L, et al. Role of the short isoform of myosin light chain kinase in the contraction of cultured smooth muscle cells as examined by its down-regulation. Proc Natl Acad Sci USA 2002; 99 : 9556-9561. 